\title{
How to Manage Resistant Schizophrenia
}

\author{
Bitar $\mathrm{M}^{*}$, Ouanass A \\ Ar-razi Psychiatric University Hospital, Salé, Faculty of Medicine and Pharmacy Rabat, Morocco
}

DOI: $10.36348 /$ SJM.2019.v04i09.003

| Received: 25.08.2019 | Accepted: 08.09.2019 | Published: 24.09.2019

*Corresponding author: Bitar

\section{Abstract}

Introduction: Schizophrenia is a chronic and debilitating psychiatric condition that constitutes a real public health problem. Antipsychotics have changed the management of schizophrenia, but the cases of resistance are more and more important. Methodology: Retrospective descriptive study carried out at the Razi hospital concerning the files of patients with resistant schizophrenia hospitalized during the period spanning 3 years, from 2013 to 2015. Inclusion criteria: Cases of schizophrenia and resistant schizoaffective disorder are defined according to DSM 5 criteria and Kane's resistance criteria. Exclusion criteria: Insufficient clinical information on the file Patients with neurological disease or intellectual disability. Statistical tool: SPSS 20. Results: The average age is 33 years old. An age range between 19 and 53 years old. All our patients are male. In our sample of 33 patients, $64.3 \%$ have problematic drug use (tobacco, cannabis ...). $92.9 \%$ of our patients are schizophrenic and $7.1 \%$ have schizoaffective disorder. The age of onset of the disease is around 21 years old. Half of our patients had haloperidol as initial therapy. The diagnosis time of the disease resistance is on average 2 years. $78.6 \%$ of our patients were treated with clozapine alone, $13.3 \%$ with clozapine + antipsychotic and $7.1 \%$ with clozapine + thymoregulator. In $41 \%$ of the cases there was an improvement under these treatments and no response in $59 \%$ of the patients.

Key words: Schizophrenia, resistance, management.

Copyright @ 2019: This is an open-access article distributed under the terms of the Creative Commons Attribution license which permits unrestricted use, distribution, and reproduction in any medium for non-commercial use (NonCommercial, or CC-BY-NC) provided the original author and source are credited.

\section{INTRODUCTION}

Schizophrenia is a chronic and debilitating psychiatric condition that constitutes a real public health problem [1]. Since the 1950s, the contribution of conventional antipsychotics, then that of atypical antipsychotics with improved tolerance, has considerably modified the management of patients suffering from schizophrenia. However, the frequency of cases that do not respond to these molecules is one of the main limitations of this therapeutic contribution [2].

This gave birth to the notion of resistant schizophrenia. Thus, it is estimated that between $20 \%$ and $30 \%$ of patients with schizophrenia have persistent psychotic symptoms despite two or more adequate antipsychotic drug trials.

Antipsychotics have changed the management of schizophrenia, but the cases of resistance are more and more important. The management of this resistance has always been a challenge for practitioners and researchers. Some therapeutic strategies have been adopted to overcome them. Clozapine alone or in combination with other therapies is still used as the most successful molecule. Sismotherapy is also used in this indication as an alternative to antipsychotics.

\section{Objective of our work}

To study the modalities of management of patients with schizophrenia resistive at Ar- azi de Salé Hospital

\section{METHODOLOGY}

This is an e retrospective study descriptive carried out in Ar-r hospital azi about folders resistant schizophrenia patients hospitalized during the period spanning 3 years, from 2013 to 2015 .

\section{Inclusion criteria}

Cases of schizophrenia and schizoaffectiveresistant disorder are defined according to DSM 5 criteria and Kane's resistance criteria.

\section{Criteria for exclusion}

I nsuffisance clinical information on file. Patients with neurological disease or intellectual disability. Descriptive and analytical statistical analysis was performed using SPSS 20 software 


\section{RESULTS}

The average age is 33 years old. An age range between 19 and 53 years old. All our patients are male. In our sample of 33 patients, $64.3 \%$ have a problematic drug problem (tobacco, cannabis, etc.). $92.9 \%$ of our patients are schizophrenic and $7.1 \%$ have schizoaffective disorder.

The age of onset of the disease is around 21 years old. Half of our patients had haloperidol as initial therapy. The diagnosis time of the disease resistance is on average 2 years. $78.6 \%$ of our patients have been treated with clozapine alone, $14,3 \%$ by clozapine antipsychotic + and $7.1 \%$ of our sample clozapine + mood stabilizer. In $41 \%$ of cases there was an improvement under these treatments and no response in $59 \%$ of patients.

\section{DISCUSSION}

The schizop hrénie represents one of the most disabling psychiatric disorders, with a prevalence of years the world around $1 \%$ [3].

Although antipsychotics are effective in the majority of patients with schizophrenia, between 5 and $25 \%$ of patients do not improve with these drugs [4].

In our study, our first deduction is the low proportion of women, which confirms the literature that suggests that resistant schizophrenia is more common in men [5]. But no argument is advanced to explain this difference.

So far, clozapine, the first atypical antipsychotic drug, is the treatment of choice in resistant schizophrenia [6]. In our sample, $78.6 \%$ of our patients have been treated with clozapine alone, 21, $4 \%$ by clozapine with another molecule following a nonresponse to it alone. In $41 \%$ of the cases there was an improvement under these treatments and no response in $59 \%$ of the patients.

The group of patients who responded to clozapine confirms the effectiveness of this molecule in the treatment-resistant schizophrenia, it is the only antipsychotic drug to have shown superior efficacy in controlling psychotic symptoms and also reduces a suicide rate and mortality from schizophrenia [7].

In clinical practice the combination of clozapine with a second antipsychotic is relatively common when clozapine alone does not result in any improvement $[8,9]$.

Risperidone and amisulpride are the antipsychotics used to potentiate the effect of clozapine in our sample. In clinical practice as well as in experimental studies the association between clozapine and other antipsychotics is the most commonly used strategy for the management of resistant schizophrenia, particularly the combination with risperidone.

Studies on amisulpride and clozapine have reported consistent efficacy, but with high rates of side effects [10]. Other potentiation strategies for clozapine are common in clinical practice such as the addition of mood stabilizers or seismotherapy. In our sample, only some patients have been treated with these therapeutic strategies. No significant improvement was observed.

Many literature data seem to emphasize the importance of intervening extensively and more early as possible in the disease to prevent and anticipate relapses, preserve or develop auton Omie, and boost cognitive function working on ' insight, the link between severity and duration of untreated psychosis seems established. Furthermore, the data confirm that clozapine should be used early ment ; while the results of our study show that the duration of the disease without treatment and the delay before the diagnosis of resistance involving the placing on clozapine have no influence on the evolution and the prognosis of the disease.

\section{CONCLUSION}

The resistant schizophrenia is pathology with heavy consequences, at the same time medical, social and economic. His care is a real challenge for the psychiatrist. The therapeutic strategies proposed must be adapted on a case by case basis, in order to obtain the best results for each patient.

In our Moroccan context, clozapine, which remains the best therapeutic option, is not always accessible. In addition, delayed response in some patients may be at the origin of therapeutic abandonment which complicates the management.

It is necessary to provide all the therapeutic means likely' to improve patient outcomes and reduce the socio-economic burden of the family.

\section{REFFERENCE}

1. Saha, S., Chant, D., Welham, J., \& McGrath, J. (2005). A systematic review of the prevalence of schizophrenia. PLoS medicine, 2(5), e141.

2. Chakos, M., Lieberman, J., Hoffman, E., Bradford, D., \& Sheitman, B. (2001). Effectiveness of second-generation antipsychotics in patients with treatment-resistant schizophrenia: a review and meta-analysis of randomized trials. American Journal of Psychiatry, 158(4), 518-526.

3. Perälä, J., Suvisaari, J., Saarni, S. I., Kuoppasalmi, K., Isometsä, E., Pirkola, S., ... \& Härkänen, T. (2007). Lifetime prevalence of psychotic and bipolar I disorders in a general population. Archives of general psychiatry, 64(1), 19-28. 
4. Brenner, H. D., Dencker, S. J., Goldstein, M. J., Hubbard, J. W., Keegan, D. L., Kruger, G., ... \& Midha, K. K. (1990). At issue: defining treatment refractoriness in schizophrenia. Schizophrenia bulletin, 16(4), 551-561.

5. Elkis, H., \& Meltzer, H. Y. (2007). Refractory schizophrenia. Revista Brasileira de Psiquiatria, 29, S41-S47.

6. Gründer, G., Hippius, H., \& Carlsson, A. (2009). The'atypicality'of antipsychotics: a concept reexamined and re-defined. Nature Reviews Drug Discovery, 8(3), 197.

7. Lejoyeux, M., Leon, E., \& Rouillon, F. (1994). Prevalence and risk factors of suicide and attempted suicide. L'Encephale, 20(5), 495-503.
8. Buckley, P., Miller, A., Olsen, J., Garver, D., Miller, D. D., \& Csernansky, J. (2001). When symptoms persist: clozapine augmentation strategies. Schizophrenia Bulletin, 27(4), 615-628.

9. Mouaffak, F., Tranulis, C., Gourevitch, R., Poirier, M. F., Douki, S., Olié, J. P., \& Gourion, D. (2006). Augmentation strategies of clozapine with antipsychotics in the treatment of ultraresistant schizophrenia. Clinical neuropharmacology, 29(1), 28-33.

10. Potter, W. Z., Ko, G. N., Zhang, L. D., \& Yan, W. (1989). Clozapine in China: a review and preview of US/PRC collaboration. Psychopharmacology, 99, S87-S91. 